\title{
Stakeholder Delphi-perception analysis on impacts and responses of acid rain on agricultural ecosystems in the Vietnamese upland
}

\section{Autores}

Ha T. T. Pham, An Thinh Nguyen, Thuong T. H. Nguyen, Luc Hens

\begin{abstract}
Vietnam is one of most vulnerable countries to acid rain in Asia. In the Vietnamese Northern Mountains, acid rainwater affects negatively to local agricultural ecosystems. This paper analyzes how major agricultural stakeholders living in the mountains assess the impacts of acid rain and their responses on agricultural ecosystems. A two-round Stakeholder Delphi combined with the pressure-state-response (PSR) model allows ranking effects, mitigation and adaptation measures. Eight themes, 14 sub-themes, and 35 indicators for acid rain are structured in the PSR model. The results show that deforestation and rainfall variability relate to changes in the concentrations of acid ions in rainwater. Energy consumption in the industry and transportation, chemical fertilizer use in agriculture, and air pollution from neighboring areas contribute significantly to acid rain. Acid rain affects agriculture and decreases crop yields, causes arable land loss, reduces nutrients and organic matter, and accumulates heavy metals. Panel members perceive that applying local knowledge in agricultural practices, rational energy use, promotion of integrated agricultural policies, and changing farmer behaviors are measures to mitigate acid rain and its adverse effects. The results contribute to a vision on local adaptation actions and policy to foster the capacity and the resilience of major local groups.

Palabras clave
\end{abstract}

Acid rain, Acidification, Stakeholder Delphi survey, Pressure-state-response (PSR), Agricultural ecosystems, Vietnamese Northern Mountains 